\title{
A study to Assess The Effectiveness of Structured Teaching Program on Knowledge Regarding Newborn Care and Danger Signs of New Born among The Postnatal Mothers in Kirumambakkam PHC, Puducherry. ${ }^{*}$ Sumathy.P, ${ }^{* *}$ Geetha.C, ${ }^{* * *}$ Rajeswari.S
}

\begin{abstract}
:
Objectives: To assess the Effectiveness of Structured Teaching Program on knowledge regarding newborn care and danger signs of new born among the Postnatal mothers in Kirumambakkam PHC, Puducherry. Methodology: Quantitative approach and a Pre experimental design was adopted. 50 postnatal mothers who fulfilled the inclusion criteria were selected for the study. Non-probability purposive sampling technique was used to select the samples. The level of knowledge was assessed by using structured knowledge questionnaire. The pretest was administered to the postnatal mothers and on the same day a structured teaching was imparted to the mothers. After 7 days the posttest level of knowledge was assessed. Results: The study findings revealed that the pretest mean score of knowledge was 24.23 with standard deviation of 5.981 and the posttest mean score was 40.52 with standard deviation of 8.902. the calculated paired ' $t$ ' value 10.50 was found to be statistically highly significant at $p<0.001$ level which showed the effectiveness of structured teaching program regarding newborn care and danger signs of new born among the postnatal mothers. Conclusion: Maternal Knowledge about neonatal care and danger signs was low inspite of the fact that RCH programme is given top priority. Therefore interventions should focus on increasing level of parental education that would go a long way to reduce neonatal morbidity and mortality
\end{abstract}

Key words: Postnatal mothers, Newborn care and Danger signs of new born

\section{INTRODUCTION:}

Newborn care is of immense importance for the proper development and healthy life. Neonatal mortality is one of the major concern all over the world, especially in developing countries. Globally an average of 3,53,000 babies are born each day around the world. The crude birth rate is 18.9 births/ 1,000 population or 255 births globally per minute or 4.3 births / second (as per Dec 2013 estimate). ${ }^{1}$ The incidence of newborn mortality in India is around 26 million per year that is $30 \%$ of 3.9 million global neonatal deaths (UNICEF 2014). ${ }^{2}$ Most of the neonatal deaths can be prevented with cost effective solution.

Proper parenting by the mothers for a newborn is very important as neonates need special care. Care given by a mother to 
the neonate is not just important, for their physical health, but also promote psychological and social well being. ${ }^{3}$ It is the prime responsibility of the mothers to have an adequate knowledge regarding newborn care, and its danger signs so that they can easily identify the illnesses and thereby can prevent neonatal morbidity and mortality.

Hence the researcher was interested to assess the existing level of knowledge pertaining to newborn care and neonatal danger signs and enrich the mother's knowledge by imparting a teaching programme.

\section{PROBLEM STATEMENT:}

A study to assess the Effectiveness of Structured Teaching Program on Knowledge regarding Newborn Care and Danger Signs of Newborn among Postnatal mothers in Kirumambakkam PHC, Puducherry.

\section{OBJECTIVES:}

1. To assess the level of knowledge of mothers regarding newborn care and newborn danger signs.

2. To assess the effectiveness of structured teaching programme on knowledge regarding newborn care and newborn danger signs.
3. To associate the level of knowledge with selected demographic variables.

\section{MATERIALS AND METHODS:}

The research approach is quantitative research approach and the design adopted is pre-experimental research design.The study was conducted in Kirumambakkam PHC in Puducherry.

\section{SAMPLE SIZE AND SAMPLING TECHNIQUE:}

The sample size was 50 , and the sampling technique adopted was purposive sampling technique.

\section{RESULTS:}

\section{Socio - Demographic Variables:}

Out of 50 samples majority of the mothers $18(36 \%)$ were in the age group of 1822 years and only 5(10\%) were above 28 years .With regard to education $36(72 \%)$ had an education upto10th standard. 44(88\%) were unemployed, and most of them $31(62 \%)$ were from low socio economic status. 25(50\%) were Hindus, 6(12\%) were Muslims, 19(38\%) were Christians.

Table 1: Frequency and Percentage Distribution of the Level of Knowledge regarding Newborn care and its Danger signs among Postnatal mothers, in pre- test and post -test.

\begin{tabular}{|c|c|c|c|c|}
\hline \multirow{2}{*}{$\begin{array}{c}\text { Level of } \\
\text { knowledge }\end{array}$} & \multicolumn{2}{|c|}{ Pre test } & \multicolumn{2}{c|}{ Post test } \\
\cline { 2 - 5 } $\begin{array}{c}\text { Adequate } \\
\text { knowledge }\end{array}$ & 8 & $\%$ & 30. & 60 \\
\hline $\begin{array}{c}\text { Moderately } \\
\text { adequate } \\
\text { knowledge }\end{array}$ & 14 & 28 & 8 & 16 \\
\hline $\begin{array}{c}\text { Inadequate } \\
\text { knowledge }\end{array}$ & 28 & 56 & 12 & 24 \\
\hline
\end{tabular}


The above table depicts that $8(16 \%)$ inadequate knowledge, $14(28 \%)$, had moderately adequate knowledge, and 28(56\%) had inadequate knowledge regarding newborn care, and its danger signs, in pretest, and whereas in post- test, $30(60 \%)$ gained adequate knowledge, $8(16 \%)$ gained moderately adequate knowledge and only $12(24 \%)$ continued to have inadequate knowledge.

Table 2: Assessment of level of Knowledge regarding Various Aspects of Newborn care and Newborn Danger Signs in Pre- test and Post -test among Postnatal mothers

\begin{tabular}{|c|c|c|c|c|c|c|c|c|c|c|c|c|}
\hline \multirow{4}{*}{$\begin{array}{l}\text { Knowledge on various } \\
\text { aspects of newborn care and } \\
\text { Newborn danger signs }\end{array}$} & & & & & & & \multicolumn{6}{|c|}{$\mathrm{N}=\mathbf{5 0}$} \\
\hline & \multicolumn{6}{|c|}{$\begin{array}{c}\text { Level of knowledge } \\
\text { Pre-test }\end{array}$} & & & vel & $\begin{array}{l}\text { f kn } \\
\text { ost t }\end{array}$ & $\begin{array}{l}\text { wled } \\
\text { st }\end{array}$ & \\
\hline & \multicolumn{2}{|c|}{$<50 \%$} & \multicolumn{2}{|c|}{$50-75 \%$} & \multicolumn{2}{|c|}{$>75 \%$} & \multicolumn{2}{|c|}{$<50 \%$} & \multicolumn{2}{|c|}{$50-75 \%$} & \multicolumn{2}{|c|}{$>75 \%$} \\
\hline & $\mathrm{N}$ & $\%$ & $\mathrm{~N}$ & $\%$ & $\mathrm{~N}$ & $\%$ & $\mathrm{~N}$ & $\%$ & $\mathrm{~N}$ & $\%$ & $\mathrm{~N}$ & $\%$ \\
\hline Thermoregulation & 5 & 10 & 30 & 60 & 15 & 30 & 2 & 4 & 2 & 16 & 46 & 92 \\
\hline Breast feeding & 11 & 22 & 30 & 60 & 9 & 18 & 4 & 8 & 2 & 20 & 44 & 88 \\
\hline Skin care & 8 & 16 & 34 & 68 & 8 & 16 & 2 & 4 & 1 & 2 & 47 & 94 \\
\hline Prevention of infection & 10 & 20 & 13 & 26 & 26 & 52 & 6 & 12 & 4 & 8 & 40 & 80 \\
\hline Danger signs & 14 & 28 & 35 & 70 & 01 & 2 & 4 & 8 & 2 & 4 & 44 & 88 \\
\hline
\end{tabular}

Table 2: Denotes that in pre- test $30(60 \%)$ of the mothers had moderately adequate knowledge regarding breast feeding and thermoregulation, 26(52\%) had adequate knowledge regarding prevention of infection, and $34(68 \%)$ and $35(70 \%)$ had moderately adequate knowledge regarding skin care and danger signs respectively.

In post- test, 46(92\%) of the mothers gained adequate knowledge regarding thermoregulation, $44(88 \%)$ gained adequate knowledge regarding breast feeding and danger signs, 40(80\%) gained adequate knowledge regarding prevention of infection.

Table 3: Effectiveness of Structured Teaching Program on Knowledge Regarding Newborn Care and Danger Signs of Newborn among Post Natal Mothers.

$\mathbf{N}=\mathbf{5 0}$

\begin{tabular}{|c|c|c|c|c|}
\hline \multirow{2}{*}{} & \multicolumn{2}{|c|}{ Knowledge } & \multirow{2}{*}{ Paired t value } & \multirow{2}{*}{ P value } \\
\cline { 2 - 3 } & Mean & SD & & \\
\hline Pre test & 24.23 & 5.981 & \multirow{2}{*}{10.50} & $<0.001$ \\
\hline Post test & 40.52 & 8.902 & & \\
\hline
\end{tabular}

The above table indicates the mean in pre test was 24.23 with a standard deviation of 5.981, and in the post test was 40.52 with a SD of 8.902. the $t$ value was 10.50 which was highly significant at $\mathrm{p}<0.001$ level which can be attributed to the effectiveness of STP.

There was a significant association between the level of knowledge and demographic variables such as age, educational status and occupation, that was statistically significant at $\mathrm{p}<0.000$ level 


\section{DISCUSSION:}

Reduction of neonatal mortality to acceptable level is impossible without good maternal knowledge regarding newborn care and newborn danger signs.

In this study, only $8(16 \%)$ had adequate knowledge regarding newborn care and neonatal danger signs. A similar study done in Ethiopia reveals that only $18.2 \%$ of mothers had good knowledge regarding newborn danger signs, which implies that greater initiative has to be taken to empower the community to improve the maternal knowledge. ${ }^{4}$

This finding is also supported by another study done at Mangalore where $10 \%$ of respondents had good knowledge, $26 \%$ poor knowledge , 64\% moderately adequate knowledge related to newborn care and neonatal danger signs. ${ }^{5}$

The present study indicates the mean knowledge in pre test was 24.23 with a standard deviation of 5.981, and in the post test was 40.52 with a SD of 8.902 and the t value was 10.50 which was highly significant at $\mathrm{p}<0.001$ level which can be attributed to the effectiveness of STP.

A similar study done in Coimbatore regarding the Effectiveness of video teaching programme on knowledge regarding care of newborn among primigravid mothers revealed that the mean score during pretest was 3.33 and post test mean was 18.88 and the obtained t value was 37.26 at $\mathrm{p}<0.05$ level . It clearly depicts that imparting knowledge definitely improves the knowledge level. ${ }^{6}$

In this study, a significant association between the level of knowledge and demographic variables such as age, educational status and occupation, was statistically significant at $p<0.000$ level. A similar study done in Ethiopia reveals that Education was an important determinant factor in increasing the knowledge. The possible justification is that educated mothers are more likely to make decisions for quality health service and has improved perception of newborn care and its danger signs. ${ }^{4}$

Conclusion: Maternal Knowledge about neonatal care and danger signs was low inspite of the fact that RCH programme is given top priority. Therefore interventions should focus on increasing level of parental education that would go a long way to reduce neonatal morbidity and mortality.

Bibliography:

1. Reza Sharafi, Hassan Esmaeeli Knowledge Assessment of Neonatal Care among Postnatal Mothers "Journal Management System" 2013, 4(1) 28-31.

2. www.UNICEF.org

3. Mbada C.E. Assess the Knowledge regarding newborn care,"Bangladesh Journal of Medicine"2012, 14(2) 147-152.

4. Solomon GedluNigatu, AbebawGebeyekuWorku et.al., Level of mother's knowledge about neonatal danger signs and associated factors in North West of Ethiopia - a Community based study, Bio Med Central , Vol.8

5. Fernades JP Souza A study to assess the awareness of mothers on danger signs of newborn with a view to prepare information Booklet in selected Hospital International Journal of Health, Science \& Research 2013, 5(1), 167-68.

6. M.D. Santhi\&Kokilavani Effectiveness of video assisted teaching programme on knowledge regarding physical care of newborn among primigravid mothers at Urban Health Maternity Centres Coimbatore www.reviewsofprogress.org, 2013 1(8). 